\title{
Point-of-care lactate and creatinine analysis for sick obstetric patients at Queen Elizabeth Central Hospital in Blantyre, Malawi: A feasibility study
}

\section{SA Glasmacher ${ }^{1}$, P Bonongwe $^{2}$, W Stones ${ }^{1,3,4}$}

\author{
1. School of Medicine University of St Andrews United Kingdom \\ 2. Department of Obstetrics and Gynaecology, Queen Elizabeth Central Hospital, Blantyre, Malawi \\ 3. Department of Obstetrics and Gynaecology, College of Medicine, University of Malawi, Blantyre, Malawi \\ 4. School of Public Health and Family Medicine, College of Medicine, University of Malawi, Blantyre, Malawi
}

Correspondence to: Stella A Glasmacher | E-mail: stellaglasmacher@web.de

\begin{abstract}
\section{Background}

To achieve good outcomes in critically ill obstetric patients, it is necessary to identify organ dysfunction rapidly so that life-saving interventions can be appropriately commenced. However, timely access to clinical chemistry results is problematic, even in referral institutions, in the sub-Saharan African region. Reliable point-of-care tests licensed for clinical use are now available for lactate and creatinine.
\end{abstract}

\section{Aim}

We aimed to assess whether implementation of point-of-care testing for lactate and creatinine is feasible in the obstetric unit at the Queen Elizabeth Central Hospital $(\mathrm{QECH})$ in Blantyre, Malawi, by obtaining the opinions of clinical staff on the use of these tests in practice.

\section{Methods}

During a two-month evaluation period nurse-midwives, medical interns, clinical officers, registrars, and consultants were given the opportunity to use StatStrip ${ }^{\oplus}$ and StatSensor ${ }^{\circ}$ (Nova Biomedical, Waltham, USA) devices, for lactate and creatinine estimation, as part of their routine clinical practice in the obstetric unit. They were subsequently asked to complete a short questionnaire.

\section{Results}

Thirty-seven questionnaires were returned by participants: 22 from nurse-midwives and the remainder from clinicians. The mean satisfaction score for the devices was 7.6/10 amongst clinicians and 8.0/10 amongst nurse-midwives. The majority of participants stated that the obstetric high dependency unit (HDU) was the most suitable location for the devices. For lactate, 31 participants strongly agreed that testing should be continued and 24 strongly agreed that it would influence patient management. For creatinine, 29 strongly agreed that testing should be continued and 28 strongly agreed that it would influence their patient management. Twenty participants strongly agreed that they trust point-of-care devices.

\section{Conclusions}

Point-of-care clinical chemistry testing was feasible, practical, and well received by staff, and was considered to have a useful role to play in the clinical care of sick obstetric patients at this referral centre.

\section{Introduction}

In the context of obstetric practice, there are difficulties in the early recognition of severe sepsis and renal compromise. Obstetric patients are relatively young and are usually previously healthy, so the development of obvious clinical signs may occur late in the evolution of these conditions. Thus, organ failure is often already established by the time a firm diagnosis is made. At Queen Elizabeth Central Hospital $(\mathrm{QECH})$ in Blantyre, Malawi, sepsis and preeclampsia are amongst the most common causes of maternal mortality. ${ }^{1}$

In low-resource settings, point-of-care devices have been shown to greatly enhance the feasibility of biochemical testing. ${ }^{2}$ As diagnostic tools, such devices can be used quickly and easily by auxiliary health personnel, ${ }^{3}$ and as such they are usually well received by staff and contribute to improved medical care. ${ }^{4}$ Furthermore, point-of-care testing may enable more efficient use of scarce resources, leading to reduced hospital stay durations, fewer unnecessary hospital admissions, and reduced use of blood products. ${ }^{5}$ In Malawi, the cost of laboratory investigations is a major challenge, and while point-of-care devices are often used for research studies, they are scarcely available for routine use. Potential difficulties associated with the introduction of point-of-care testing into the clinical setting include logistic problems, poor documentation of test results, lack of critical value notification systems, and poor quality control. ${ }^{6}$ However, these challenges may be overcome by staff training.

Lactate and creatinine testing are especially valuable for http://dx.doi.org/10.4314/mmj.v28i1.4 identification of critical illness amongst obstetric patients. Hyperlactataemia is common in critically ill patients and is thought to arise as a result of catecholamine release during shock states. ${ }^{7}$ Lactate predicts mortality in intensive care patients ${ }^{8}$ and its use to guide resuscitation reduces hospital mortality. ${ }^{9}$ Creatinine facilitates early detection of pregnancy-related acute kidney injury, a condition associated with devastating maternal and foetal consequences. ${ }^{10}$ As of March 2016, serum lactate analysis is not currently offered at QECH, while creatinine analysis and feedback of results may take up to three days via the main hospital laboratory.

The aim of this study was to evaluate whether the implementation of point-of-care devices for lactate and creatinine is feasible in the Department of Obstetrics and Gynaecology at QECH. Specific objectives included exploration of staff opinions on whether point-of-care devices for lactate and creatinine are easy to use, influence patient management, and on if there is potential for future use and sustainability. Furthermore, the study sought to determine which cadre of staff is the most appropriate for handling point-of-care clinical chemistry devices and the most suitable location of the devices within the unit, including the obstetric admissions unit, labour ward, and obstetrics and gynaecology high dependency unit (HDU).

\section{Methods}

StatStrip Xpress ${ }^{\circledR}$ lactate meters and StatSensor Xpress ${ }^{\circledR}$ creatinine meters and test strips (Nova Biomedical, Waltham, USA), licensed internationally for clinical applications, were 
placed in the Department of Obstetrics and Gynaecology at QECH between June and July 2015 as part of a pilot study testing the feasibility of hand- held point-of-care devices. Staff were briefed on the correct operation of these devices in groups or individually and user information materials were provided including normal reference ranges. Staff were encouraged to employ the devices in their routine clinical practice when they considered it appropriate for patient care. Feasibility of use was explored in different wards of the department, including the labour ward, obstetric admissions unit, HDU, and postnatal ward.

Creatinine test strips and quality control solutions were stored in the unit refrigerator, lactate strips and solutions were stored at room temperature, and quality control tests using standard solutions for lactate and creatinine were performed regularly according to the product literature.

After six weeks, staff were presented with anonymous, paperbased questionnaires comprising 15 items that enquired about their views on point-of-care testing for lactate and creatinine in the department. All members of clinical staff employed in the Department of Obstetrics and Gynaecology at QECH who had used the devices, or results from them, were eligible for participation. Questions focused on the overall satisfaction, perceived ease of use, any difficulties experienced, and who the respondents considered should be responsible for handling these devices.

Furthermore, participants were asked to rate whether testing for lactate and creatinine was useful, whether point-of-care testing would influence patient management, whether it should be continued, whether it would increase efficiency, the types of patients and locations where it would be most useful, and how much they trust results generated by the devices. As serum creatinine analysis is available from the hospital laboratory, participants were also asked if they preferred point-of-care testing to laboratory analysis. Participants were asked to rate their level of agreement or disagreement with each questionnaire item by selecting one of the following responses: "strongly agree", "somewhat agree", "neither agree or disagree", "somewhat disagree", "strongly disagree" and "don't know". Results for overall satisfaction and perceived ease of use are presented as means and standard deviations (SD).

Exemption from ethics review was granted by the University of Malawi's College of Medicine Research and Ethics Committee (COMREC) under reference P.04/15/1723.
Approval was granted by the University Teaching and Research Ethics Committee (UTREC), at the University of St Andrews, under reference MD11557.

\section{Results}

No member of staff refused to participate. A total of 37 questionnaires were returned by participants: 22 from nursemidwives, eight from medical interns, three from registrars, two from consultants, one from a clinical officer, and one from a final year medical student. For reporting here, staff other than nurse-midwives are referred to as clinicians. Six clinicians had used the devices 1 or 2 times, two 3 to 7 times and, one more than 8 times. Among nurse-midwives, five had used the devices 1 or 2 times, five had used them 3 to 7 times, and three had used them more than 8 times. On a scale of 0 to 10 , whereby 10 indicated "extremely satisfied", the mean overall score for satisfaction with the devices was $7.6 \pm 1.4$ amongst clinicians and $8.0 \pm 1.4$ amongst nursemidwives. Mean ease-of-use scores were $9.1 \pm 1.0$ and 9.0 \pm 1.5 by clinicians and nurse-midwives, respectively. Both groups most commonly stated that nurse-midwives should mainly be responsible for point-of-care testing, followed by "all members of staff". Three clinicians had experienced difficulties with point-of-care testing, compared to two nurse-midwives. Difficulties mainly related to error messages; however, these almost always resulted from poor technique during early use rather than intrinsic faults of the devices and were resolved and explained quickly by the investigators. It appeared that two participants had misread the answer options "strongly disagree" and "strongly agree" in the second part of the survey, as they had rated the meters positively in the first part or commented favourably in response to the open-ended questions ("They should be enrolled in all central hospitals in Malawi'"). The answers of these participants were therefore modified to compensate for this error.

Thirty-one participants strongly agreed and two somewhat agreed that point-of-care testing for lactate should be continued; 22 participants strongly agreed and 13 somewhat agreed that point-of-care testing for lactate is useful in the obstetrics and gynaecology wards. Similarly, 24 participants strongly agreed and 10 somewhat agreed that results from point-of-care lactate devices would influence the management of their patients. Thirty participants strongly agreed and three somewhat agreed that lactate testing is useful in the HDU to monitor sick patients (Table 1).

Table 1: Staff opinions regarding point-of-care testing for lactate

\begin{tabular}{|c|c|c|c|c|c|c|c|c|}
\hline \multirow[b]{2}{*}{ Questionnaire prompt } & \multirow[b]{2}{*}{ Staff group } & \multicolumn{7}{|c|}{ Frequency (\%) } \\
\hline & & $\begin{array}{l}\text { Strongly } \\
\text { disagree }\end{array}$ & $\begin{array}{c}\text { Somewhat } \\
\text { disagree }\end{array}$ & $\begin{array}{c}\text { Neither agree } \\
\text { nor disagree }\end{array}$ & $\begin{array}{c}\text { Somewhat } \\
\text { agree }\end{array}$ & $\begin{array}{l}\text { Strongly } \\
\text { agree }\end{array}$ & Don't know & No response \\
\hline \multirow{3}{*}{$\begin{array}{l}\text { POC testing for lactate } \\
\text { should be continued in } \\
\text { the obstetrics and } \\
\text { gynaecology wards }\end{array}$} & Nurse-midwives & 0 & 0 & 0 & $1(5)$ & $19(86)$ & $1(5)$ & $1(5)$ \\
\hline & Clinicians & $1(7)$ & 0 & $1(7)$ & $1(7)$ & $12(80)$ & 0 & 0 \\
\hline & Total & $1(3)$ & $\mathbf{0}$ & $1(3)$ & $2(5)$ & $31(83)$ & $1(3)$ & $1(3)$ \\
\hline \multirow{3}{*}{$\begin{array}{l}\text { POC testing for lactate is } \\
\text { useful in the obstetrics } \\
\text { and gynaecology wards }\end{array}$} & Nurse-midwives & 0 & 0 & 0 & $8(36)$ & $13(59)$ & $1(4.5)$ & 0 \\
\hline & Clinicians & $1(7)$ & 0 & 0 & $5(33)$ & $9(60)$ & 0 & 0 \\
\hline & Total & $1(3)$ & 0 & $\mathbf{0}$ & $13(35)$ & $22(59)$ & $1(3)$ & 0 \\
\hline \multirow{3}{*}{$\begin{array}{l}\text { POC testing for lactate } \\
\text { would influence the } \\
\text { management of my } \\
\text { patients }\end{array}$} & Nurse-midwives & 0 & 0 & 0 & $4(18)$ & $16(72)$ & $1(5)$ & $1(5)$ \\
\hline & Clinicians & $1(7)$ & 0 & 0 & $6(40)$ & $8(53)$ & 0 & 0 \\
\hline & Total & $1(3)$ & $\mathbf{0}$ & $\mathbf{0}$ & $10(27)$ & $24(64)$ & $1(3)$ & $1(3)$ \\
\hline \multirow{3}{*}{$\begin{array}{l}\text { POC testing for lactate } \\
\text { would be useful for } \\
\text { monitoring sick patients } \\
\text { in HDU }\end{array}$} & Nurse-midwives & 0 & 0 & 0 & $1(5)$ & $17(77)$ & $2(9)$ & $2(9)$ \\
\hline & Clinicians & 0 & 0 & 0 & $2(13)$ & $13(87)$ & 0 & 0 \\
\hline & Total & $\mathbf{0}$ & $\mathbf{0}$ & $\mathbf{0}$ & $3(8)$ & $30(82)$ & $2(5)$ & $2(5)$ \\
\hline
\end{tabular}


Table 2: Staff opinions regarding point-of-care testing for creatinine

\begin{tabular}{|c|c|c|c|c|c|c|c|c|}
\hline \multirow[b]{2}{*}{ Questionnaire prompt } & \multirow[b]{2}{*}{ Staff group } & \multicolumn{7}{|c|}{ Frequency $(\%)$} \\
\hline & & $\begin{array}{l}\text { Strongly } \\
\text { disagree }\end{array}$ & $\begin{array}{c}\text { Somewhat } \\
\text { disagree }\end{array}$ & $\begin{array}{l}\text { Neither agree } \\
\text { nor disagree }\end{array}$ & $\begin{array}{c}\text { Somewhat } \\
\text { agree }\end{array}$ & $\begin{array}{c}\text { Strongly } \\
\text { agree }\end{array}$ & Don't know & No response \\
\hline \multirow{3}{*}{$\begin{array}{l}\text { POC testing for creatinine } \\
\text { should be continued in the } \\
\text { obstetrics and gynaecology } \\
\text { wards }\end{array}$} & Nurse-midwives & 0 & 0 & 0 & $3(14)$ & $16(72)$ & 0 & $3(14)$ \\
\hline & Clinicians & $1(7)$ & 0 & 0 & $1(7)$ & $13(86)$ & 0 & 0 \\
\hline & Total & $1(3)$ & $\mathbf{0}$ & $\mathbf{0}$ & $4(11)$ & $29(78)$ & $\mathbf{0}$ & $3(8)$ \\
\hline \multirow{3}{*}{$\begin{array}{l}\text { POC testing for creatinine } \\
\text { is useful in the obstetrics } \\
\text { and gynaecology wards }\end{array}$} & Nurse-midwives & 0 & 0 & 0 & $6(27)$ & $13(59)$ & 0 & $3(14)$ \\
\hline & Clinicians & $1(7)$ & 0 & 0 & $1(7)$ & $13(86)$ & 0 & 0 \\
\hline & Total & $1(3)$ & $\mathbf{0}$ & $\mathbf{0}$ & $7(19)$ & $26(70)$ & $\mathbf{0}$ & $3(8)$ \\
\hline \multirow{3}{*}{$\begin{array}{l}\text { POC testing for creatinine } \\
\text { would influence the } \\
\text { management of my } \\
\text { patients }\end{array}$} & Nurse-midwives & 0 & 0 & 0 & $5(23)$ & $15(68)$ & 0 & $2(9)$ \\
\hline & Clinicians & $1(7)$ & 0 & 0 & $1(7)$ & $13(86)$ & 0 & 0 \\
\hline & Total & $1(3)$ & $\mathbf{0}$ & $\mathbf{0}$ & $6(16)$ & $28(76)$ & $\mathbf{0}$ & $2(5)$ \\
\hline \multirow{3}{*}{$\begin{array}{l}\text { POC testing for creatinine } \\
\text { would be useful for } \\
\text { monitoring sick patients in } \\
\text { HDU }\end{array}$} & Nurse-midwives & $1(5)$ & $1(5)$ & 0 & $2(9)$ & $14(64)$ & 0 & $4(18)$ \\
\hline & Clinicians & 0 & $2(13)$ & $1(7)$ & $1(7)$ & $9(60)$ & $2(13)$ & 0 \\
\hline & Total & $1(3)$ & $3(8)$ & $1(3)$ & $3(8)$ & $23(62)$ & $2(5)$ & $4(11)$ \\
\hline
\end{tabular}

POC = point-of-care; $\mathrm{HDU}=$ high dependency unit

Twenty-nine participants strongly agreed and four somewhat agreed that point-of-care creatinine testing should be continued, while 26 participants strongly agreed and seven somewhat agreed that it is useful. Twenty-eight participants strongly agreed and six somewhat agreed that point-of-care creatinine analysis would influence patient management. Creatinine can be analysed by the hospital laboratory; nevertheless, 23 participants strongly agreed and three somewhat agreed that creatinine analysis by point-ofcare testing is preferable to that carried out by the hospital laboratory (Table 2).

Twenty-six participants strongly agreed and seven somewhat agreed that point of care testing would improve efficiency in the obstetrics and gynaecology wards. Most staff trusted the results from point-of-care meters: 20 participants strongly agreed and nine somewhat agreed to this (Table 3 ).

Quality control checks were consistently within their normal ranges. Owing to power outages, there were a few interruptions in refrigerator power; however, these were of short duration and were unlikely to have adversely affected the creatinine test strips. Inadequate documentation of test results and failure to recognise abnormal results were not observed during this pilot study.

Many members of staff commented favourably on how the meters aided patient care ("I think it helps make critical decisions quickly" - registrar) and asked for continuation of the study ("Please continue supplying us with testing kits for continuation of testing" - nurse-midwife).

\section{Discussion}

The findings suggest that point-of-care testing for both lactate and creatinine is considered helpful for clinical care

and is favoured by staff in the obstetric unit. Point-of-care testing for lactate was considered most beneficial for use in the HDU, for regular monitoring of sick patients, to guide clinicians on a patient's progress or to alert clinicians to deterioration. The availability of hand-held meters for this purpose considerably enhanced the availability and feasibility of lactate measurements, meaning that lactate could be used as a dynamic marker for risk stratification of critically ill patients in the obstetric HDU. A recent study confirmed that dynamic indices of lactate are superior predictors of mortality than static indices, since they describe not only the magnitude but also the trend of hyperlactataemia over time. $^{11,12}$ Nevertheless, static lactate indices also have an important role, for example, in guiding clinical decisions as to who should be admitted to a high dependency model of care. Such decisions may have profound implications, not only on patient well-being, but also on the appropriate use of scarce resources by using available beds, staff time, and investigations for those who would most benefit from these provisions. Thus, point-of-care testing can facilitate the effective use of a limited number of HDU beds and accelerate smooth "step-up" care for patients who deteriorate and "step-down" care for those ready to transfer to a postnatal ward. ${ }^{13}$

While it was beyond the scope of this feasibility study to formally investigate point-of-care testing in relation to patient outcomes or to define its cost-effectiveness, evidence from a study in emergency department patients with suspected sepsis suggests that the introduction of point-of-care lactate devices reduces the time to administration of intravenous fluids, intensive care unit admission when needed, and, indeed, mortality. ${ }^{14}$ Routine implementation of point-of-

Table 3: Staff opinions regarding point-of-care testing in general

\begin{tabular}{|c|c|c|c|c|c|c|c|c|}
\hline \multirow[b]{2}{*}{ Questionnaire prompt } & \multirow[b]{2}{*}{ Staff group } & \multicolumn{7}{|c|}{ Frequency (\%) } \\
\hline & & $\begin{array}{l}\text { Strongly } \\
\text { disagree }\end{array}$ & $\begin{array}{l}\text { Somewhat } \\
\text { disagree }\end{array}$ & $\begin{array}{l}\text { Neither agree } \\
\text { nor disagree }\end{array}$ & $\begin{array}{l}\text { Somewhat } \\
\text { agree }\end{array}$ & $\begin{array}{c}\text { Strongly } \\
\text { agree }\end{array}$ & Don't know & No response \\
\hline \multirow{3}{*}{$\begin{array}{l}\text { POC testing for creatinine } \\
\text { should be continued in the } \\
\text { obstetrics and gynaecology } \\
\text { wards }\end{array}$} & Nurse-midwives & o & $\mathrm{o}$ & $\mathrm{o}$ & $3(14)$ & $16(72)$ & o & $3(14)$ \\
\hline & Clinicians & $1(7)$ & o & o & $1(7)$ & $13(86)$ & o & o \\
\hline & Total & $1(3)$ & $\mathbf{o}$ & $\mathbf{o}$ & $4(11)$ & $29(78)$ & $\mathbf{o}$ & $3(8)$ \\
\hline \multirow{3}{*}{$\begin{array}{l}\text { POC testing for creatinine } \\
\text { is useful in the obstetrics } \\
\text { and gynaecology wards }\end{array}$} & Nurse-midwives & o & o & o & $6(27)$ & $13(59)$ & o & $3(14)$ \\
\hline & Clinicians & $1(7)$ & o & o & $1(7)$ & $13(86)$ & o & o \\
\hline & Total & 1 (3) & o & o & 7 (19) & $26(70)$ & o & $3(8)$ \\
\hline \multirow{3}{*}{$\begin{array}{l}\text { POC testing for creatinine } \\
\text { would influence the } \\
\text { management of my } \\
\text { patients }\end{array}$} & Nurse-midwives & o & o & o & $5(23)$ & $15(68)$ & o & $2(9)$ \\
\hline & Clinicians & $1(7)$ & o & o & $1(7)$ & $13(86)$ & o & o \\
\hline & Total & $1(3)$ & o & $\mathbf{o}$ & $6(16)$ & $28(76)$ & $\mathbf{o}$ & $2(5)$ \\
\hline \multirow{3}{*}{$\begin{array}{l}\text { POC testing for creatinine } \\
\text { would be useful for } \\
\text { monitoring sick patients in } \\
\text { HDU }\end{array}$} & Nurse-midwives & $1(5)$ & $1(5)$ & o & $2(9)$ & $14(64)$ & o & $4(18)$ \\
\hline & Clinicians & o & $2(13)$ & $1(7)$ & $1(7)$ & $9(60)$ & 2 (13) & o \\
\hline & Total & 1 (3) & $3(8)$ & 1 (3) & $3(8)$ & $23(62)$ & $2(5)$ & $4(11)$ \\
\hline
\end{tabular}


care testing in emergency departments of low- and middleincome countries has been reported to be associated with improved health-related outcomes and can be cost effective. ${ }^{15}$ Given the considerable burden of sepsis in referred obstetric patients, these results are likely to be transferable to specialist obstetric units in low-resource settings.

We noted that trust in the results of point-of-care devices was relatively low, with just over half of participants strongly agreeing that they trust the results. Studies have reported a close correlation in measurements between point-of-care devices and a reference standard laboratory analyser for both lactate ${ }^{16,17}$ and creatinine, ${ }^{18,19,20}$ but for staff to gain confidence in the results, an implementation strategy would need to include an initial component of validation of findings against results from an appropriate reference laboratory.

The present study was not designed to assess the influence of access to these tests to clinical decision making, outcomes, and cost-effectiveness, and the next stage will be to design appropriate implementation research to generate this knowledge, initially in large referral facilities, such as the QECH, before consideration is given to extending the approach to district-level facilities.

\section{Conclusions}

We conclude that implementation of point-of-care testing in the Department of Obstetrics and Gynaecology at QECH is worthwhile and staff felt strongly that the point-of-care consumables should be available for future continuation of point-of-care testing - "Let it continue" (nurse-midwife).

\section{Acknowledgements}

We thank the nurses and clinicians at QECH for their enthusiastic participation in this study.

\section{Conflicts of Interest}

The authors declare no conflicts of interest.

\section{Funding}

Point-of-care devices and consumables were purchased for this study and funded by the Global Health Implementation Research Group at the University of St Andrews. The manufacturer and supplier had no role in the funding, planning, or implementation of the study, data analysis, or preparation of the manuscript.

\section{References}

1. Kanyighe C, Channon A, Tadesse E, Madise N, Changole J, Bakuwa E, et al. Determinants of post-partum maternal mortality at Queen Elizabeth Central Hospital, Blantyre, Malawi: a case-control study 2001-2002. Afr J Reprod Health. 2008 Dec;(3):35-48.

2. Mtove G, Nadjm B, Hendriksen IC, Amos B, Muro F, Todd J, et al. Point-of-care measurement of blood lactate in children admitted with febrile illness to an African District Hospital. Clin Infect Dis. 2011 Sep;53(6):548-54. doi: 10.1093/cid/cir471.

3. Moore CC, Jacob ST, Pinkerton R, Meya DB, Mayanja-Kizza $\mathrm{H}$, Reynolds SJ, et al. Point-of-care lactate testing predicts mortality of severe sepsis in a predominantly HIV type 1-infected patient population in Uganda. Clin Infect Dis. 2008 Jan;46(2):215-22. doi: $10.1086 / 524665$.

4. Ivers LC, Mukherjee JS. Point of care testing for antiretroviral therapy-related lactic acidosis in resource-poor settings. AIDS. 2006 Mar 21;20(5):779-80.

5. Price CP. Point of care testing. BMJ. 2001 May 26;322(7297):12858.

6. Kost GJ, Ehrmeyer SS, Chernow B, Winkelman JW, Zaloga GP, http://dx.doi.org/10.4314/mmj.v28i1.4
Dellinger RP, et al. The laboratory-clinical interface: point-of-care testing. Chest. 1999 Apr;115(4):1140-54.

7. Levy B, Desebbe O, Montemont C, Gibot S. Increased aerobic glycolysis through beta2 stimulation is a common mechanism involved in lactate formation during shock states. Shock. 2008 Oct;30(4):417-21. doi: 10.1097/SHK.0b013e318167378f.

8. Kruse O, Grunnet N, Barfod C. Blood lactate as a predictor for inhospital mortality in patients admitted acutely to hospital: a systematic review. Scand J Trauma Resusc Emerg Med. 2011 Dec 28;19:74. doi: 10.1186/1757-7241-19-74.

9. Jansen TC, van Bommel J, Schoonderbeek FJ, Sleeswijk Visser SJ, van der Klooster JM, Lima AP, et al. Early lactate-guided therapy in intensive care unit patients: a multicenter, open-label, randomized controlled trial. Am J Respir Crit Care Med. 2010 Sep 15;182(6):752-61. doi: 10.1164/rccm.200912-1918OC.

10. Siribamrungwong M, Chinudomwong P. Relation between acute kidney injury and pregnancy-related factors. Journal of Acute Disease. 2016 Jan;5(1):22-8.

11. Nichol A, Bailey M, Egi M, Pettila V, French C, Stachowski E, et al. Dynamic lactate indices as predictors of outcome in critically ill patients. Crit Care. 2011;15(5):R242. doi: 10.1186/cc10497.

12. Zhang Z, Xu X. Lactate clearance is a useful biomarker for the prediction of all-cause mortality in critically ill patients: a systematic review and meta-analysis. Crit Care Med. 2014 Sep;42(9):2118-25. doi: 10.1097/CCM.0000000000000405.

13. Buchmann E, Stones W, Thomas. Preventing deaths from complications of labour and delivery. Best Practice \& Research Clinical Obstetrics \& Gynaecology. Forthcoming 2016.

14. Singer AJ, Taylor M, LeBlanc D, Williams J, Thode HC. ED bedside point-of-care lactate in patients with suspected sepsis is associated with reduced time to IV fluids and mortality. Am J Emerg Med. 2014 Sep;32(9):1120-4. doi: 10.1016/j.ajem.2014.06.027.

15. Khan M, Brown N, Mian AI. Point-of-care lactate measurement in resource-poor settings. Arch Dis Child. 2016 Apr;101(4):297-8. doi: 10.1136/archdischild-2015-309484. Epub 2015 Nov 18.

16. Acierno MJ, Johnson ME, Eddleman LA, Mitchell MA. Measuring statistical agreement between four point of care (POC) lactate meters and a laboratory blood analyzer in cats. J Feline Med Surg. 2008 Apr;10(2):110-4.

17. Gaieski DF, Drumheller BC, Goyal M, Fuchs BD, Shofer FS, Zogby K. Accuracy of handheld point-of-care fingertip lactate measurement in the emergency department. West J Emerg Med. 2013 Feb;14(1):58-62. doi: 10.5811/westjem.2011.5.6706.

18. Srihong C, Pangsapa K, Chuaboonmee K, Kotipan Y, Charuruks N. Evaluation of the analytical performance of the nova StatSensor creatinine meter for blood testing. J Med Assoc Thail. 2012 Sep;95(9):1225-31.

19. Schnabl KL, Bagherpoor S, Diker P, Cursio C, Dubois J, Yip PM. Evaluation of the analytical performance of the Nova StatSensor creatinine meter and reagent strip technology for whole blood testing. Clin Biochem. 2010 Aug;43(12):1026-9. doi: 10.1016/j.clinbiochem.2010.04.055.

20. Kosack CS, de Kieviet W, Bayrak K, Milovic A, Page AL. Evaluation of the Nova StatSensor ${ }^{\circledR}$ XpressTM Creatinine point-of-care handheld Analyzer. PLoS One. 2015 Apr 17;10(4):e0122433. doi: 10.1371/journal.pone.0122433. 